\title{
Electric potentials and charges on buildings and areas around deep water wells
}

\author{
Arkadiy Plugin ${ }^{1,}{ }^{*}$, Oliksii Pluhin ${ }^{2}$, Olena Palant $^{1}$, Oleksandr Konev $^{1}$, and Andrii Nikitinskii ${ }^{1}$ \\ ${ }^{1}$ Ukrainian State University of Railway Transport, Building Materials and Structures Department, \\ Feuerbach sq. 7, 61050 Kharkiv, Ukraine \\ ${ }^{2}$ Ukrainian State University of Railway Transport, Structural Mechanics and Hydraulics Department, \\ Feuerbach sq. 7, 61050 Kharkiv, Ukraine
}

\begin{abstract}
Consideration was given to the mechanisms of propagation of electric potentials in the locality of water wells and their effects on damages in the structure of buildings. Electric potentials were measured using the digital multimeter. It was established that exploitable water wells determine the division of electric charges and potentials in the adjacent territory due to the origination of macroelectrokinetic potential and the evacuation of cations from the ground. These charges and potentials can result in nonuniform strains of bases and foundations, cracks and damages in the structure of buildings and also electrocorrosion intensification nearby DC rail tracks. The measures to protect the structures from indicated destructive factors have been recommended.
\end{abstract}

\section{Introduction}

Railways have a branched water-supply infrastructure that dates back to steam-engine times. Water supply wells are situated very often near railway tracks. Railway workers state that damages done to buildings and structures situated above the wells are more vigorous in comparison with ones located in remote districts. One of the most aggressive factors that condition electrocorrosion damages in railway structures is leakage currents $[1,2]$ and electric potentials induced by them [3]. However, the influence of water supply wells on electric potentials in adjacent territories and the electrocorrosion damage to structures has not been studied yet. This research was done by the authors under the leadership of Prof. Andrey Plugin with the participation of engineer Vladimir Kasianov.

The objective of the research was to establish the mechanisms of propagation of electric potentials over the territory adjacent to a water-supply well, and also reveal their impact on damages to the structure of buildings and work out recommendations on prevention of such impacts.

\footnotetext{
* Corresponding author: pluginarkadiy@,gmail.com
} 


\section{Analytical Review of the Reference Data}

It is known that structures near DC railways and other sources are exposed to electrocorrosion. It was earlier assumed that metal structures and the iron concrete reinforcement are exposed to such impacts $[1,2]$. A.A. Staroselsky was the first to notice corrosion changes of the cement stone near the reinforcement [3]. The concrete electrocorrosion was studied in detail in [4-6]. It was established that the concrete electrocorrosion is manifested by the intensive electromigration leaching of the cement stone exposed to the pulsed unidirectional electric potential. This potential is created by trains running on DC rail sections. Papers [7] and [8] state that the alternating current and potential also condition the iron concrete and concrete electrocorrosion, though it is less intensive.

It was established in [9-12] that electric potentials can affect the concrete strength [9] and result in internal stresses [10] and cracks [11-12] in concrete structures. Papers [13-15] note the influence of potentials on stability of railway slopes, side slopes and roadbeds and also the building position on the whole [16].

Due to the above, the investigation of reasons for formation of electric potentials and charges in the locality and assessment of a risk level of their influence on buildings and structures is of great importance. Papers $[4,6,14]$ describe the mechanisms of propagation of potentials from rail tracks in the locality and structures, including their configuration on the plane, and [14-17] describe propagation mechanisms of the potentials created by the polarization of ground massifs, including transfer of ions, mainly cations, water streams, filtration, diffusion and electromigration of flows and vertical polarization of structures and buildings $[16,17]$. However, the influence that vertically extended structures, in particular water-supply wells, have on electric potentials in the territory adjacent to them and the electrocorrosion damages to structures were not studied.

\section{Research methods}

The damages to the buildings of water-supply well were studied by the method of visual inspection and measurements by taking pictures and mapping these damages.

Electric potentials (the potential difference between the measurement points) were measured with a digital PC510 multimeter Sanva according to the diagram given in Fig.1. The contact with measurement points was provided by: 0 (the well casing) immediately by the multimeter probe; 1.3 (building structures) using special copper-sulfate electrode (the contact of brass measurement plate and the structure is provided by the sponge impregnated with the saturated copper sulfate solution); 2, 4 (ground) using steel rods with a diameter of $12 \mathrm{~mm}$ driven into the ground at a depth of $0.5 \mathrm{~m}$. A value of the potential was measured at each point 10 times with a 1-minute interval and thus an average value was taken.

\section{Research data}

The water well at the Osnova station of the South railway (Kharkov, Ukraine) was studied. The well has the following parameters: the depth is $766 \mathrm{~m}$; the debit is $984 \mathrm{~m}^{3} / 24 \mathrm{hrs}$; the well casing is made of steel; the compound water intake tube is made of steel; a $380 \mathrm{~V}$ submersible pump was used. The nearest DC rail track ran at a distance of $100 \mathrm{~m}$ from the well. 


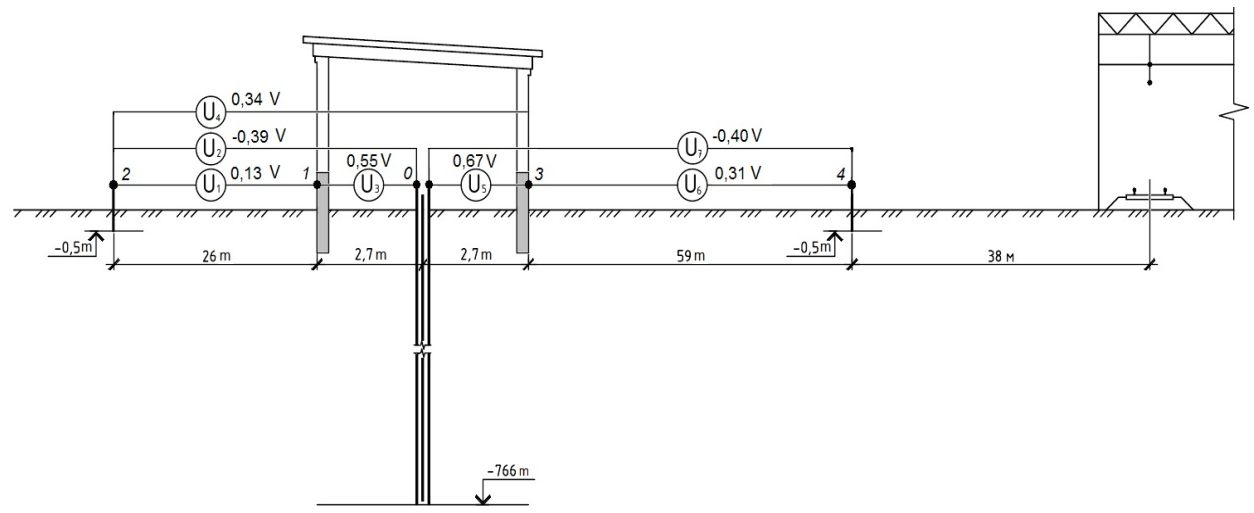

(a)

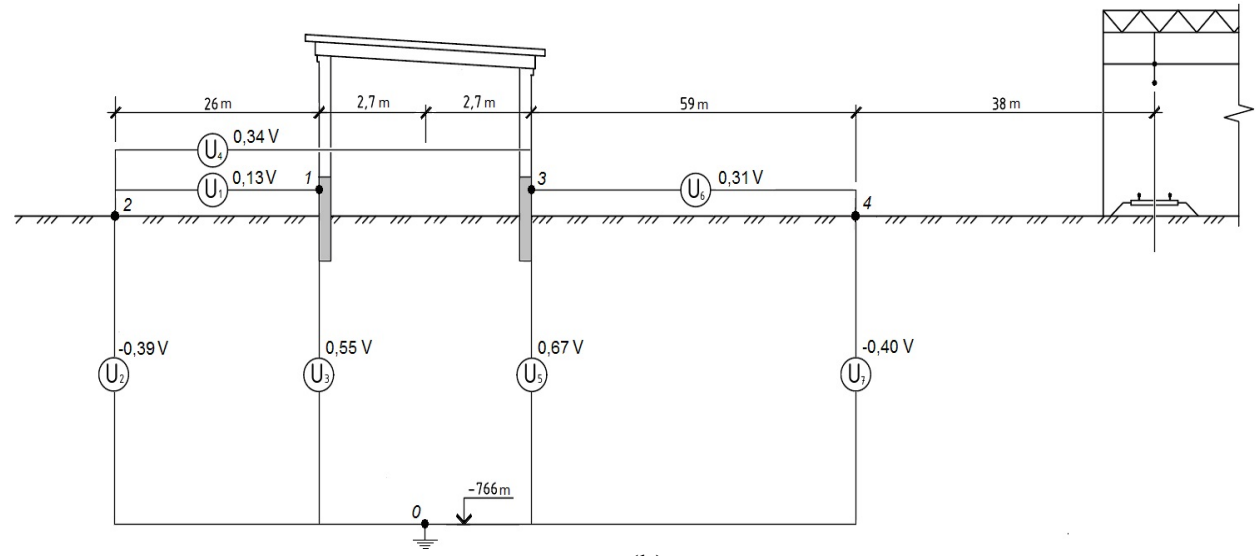

(b)

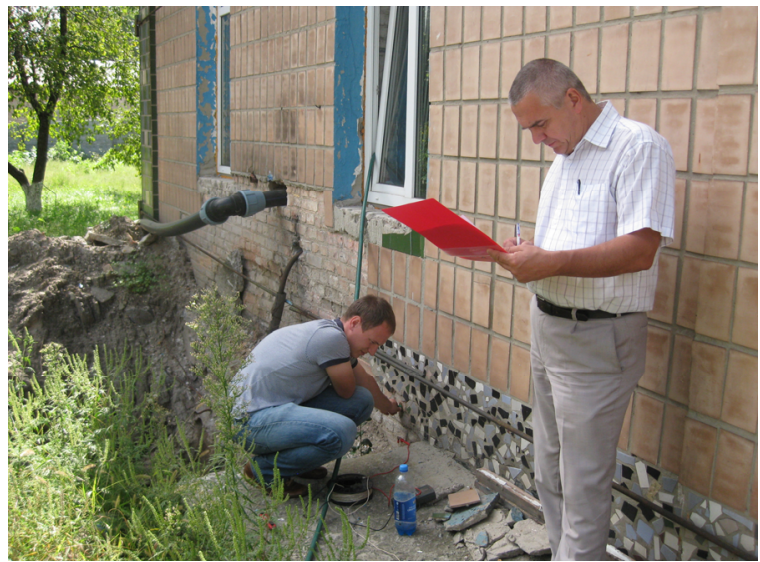

(c)

Fig.1. Measurement of electric potentials induced on water well structures: (a) measurement circuit; (b) reduced scheme; (c) Prof. Andrey Plugin and Dr. Aleksandr Konev take measurements

Fig. 2 gives the pictures of facades and appropriate maps of damages. The picture shows that the main damages are represented by opening upwards cracks in the walls and the surface fracture of the wall facing and masonry. 
Fig.1 gives the measured values of electric potentials. The potential values on the building base surface are equal to $0.55-0.67 \mathrm{~V}$ and on the ground surface these are equal to minus $0.39-0.4$ at a distance of $29-62 \mathrm{~m}$ from the well. The availability of influence that passing rail trains with electric traction have on the value of potentials and that of the switching on/off of submersible pump was not revealed.

\section{Discussing the research data}

A possible reason for absence of influence on the value of potentials that passing rail trains with electric traction can have is the current leakage from the rail track into the ground to the lower part of a casing pipe.

A change of electric potential in the locality ranging from positive values of $0.55-0.67 \mathrm{~V}$ near the well to negative of $0.39-0.4 \mathrm{~V}$ when moving away from it can be explained by the charge separation by the analogy with $[16,17]$. It is known that the Earth has an electric charge that is negative excess charge near its surface with the appropriate electric field. The field intensity near the Earth surface is equal on the average to minus $130 \mathrm{~V} / \mathrm{m}$, but it ranges from minus 1000 to plus $200 \mathrm{~V} / \mathrm{m}$. Therefore, the excess charge (and the field intensity) is changed considerably at the bottom of rivers and along their length due to the wash-out of cations from the bottom ground entrained by the water flow. This can explain repeated abnormally high strains and damages to river bridges up to their collapse (the collapse of Takomsky bridge is the most known event) $[16,17]$.

The data obtained allowed us to assume that analogous macroelectrokinetic phenomena also occur around the water-supply wells analyzed. During the water intake in the watersaturated ground surrounding the well the the flow macropotential occurs [18]. This flow washes the counterions of binary electric layers of its particles, i.e. the cations, mainly $\mathrm{Na}^{+}$, $\mathrm{K}^{+}$and $\mathrm{Ca}^{2+}$, out of the ground; they are further entrained by the pumped water. The ground particles carry an excess negative charge resulting from their potential-defining ions $\mathrm{OH}^{-}$, and the ground surrounding the well acquires a negative excess charge whose propagation range is extended with time. Not very high values of measured potentials result from the origination of counter-field due to the polarization of ground that has a high dielectric permittivity.

The excess charge presupposes the ground swelling on the foundation of the pump station building. It can result in considerable inhomogeneous strains of the foundation and, consequently, formation of cracks in the walls. The pattern of the cracks observed (Fig.2) going upwards confirms the ground swelling in the middle of the foundation.

According to Fig. 1 the upper portion of foundations has a positive potential against the ground in the depth. It results in the entrainment of cations $\mathrm{Ca}^{2+}$ from the concrete and the foundation masonry slurry into the ground and their drainage from the upper portion of walls to the bottom (Fig.3) and appearance of the potential difference between the upper and lower parts of the wall. In its turn, it results in the macroelectroosmosis of water to the upper part of walls and their moistening. When a rainy weather changes to hot, it results in the alternate moistening and drying of the facing and masonry and their damage as can be seen in Fig.2. To prevent such damages to buildings we need to provide a qualitative horizontal waterproofing not only at a level of the base top, but also at a level of the riprap. The authors recommend investigations into the possibility of bypassing the pipe casing and building structures. 

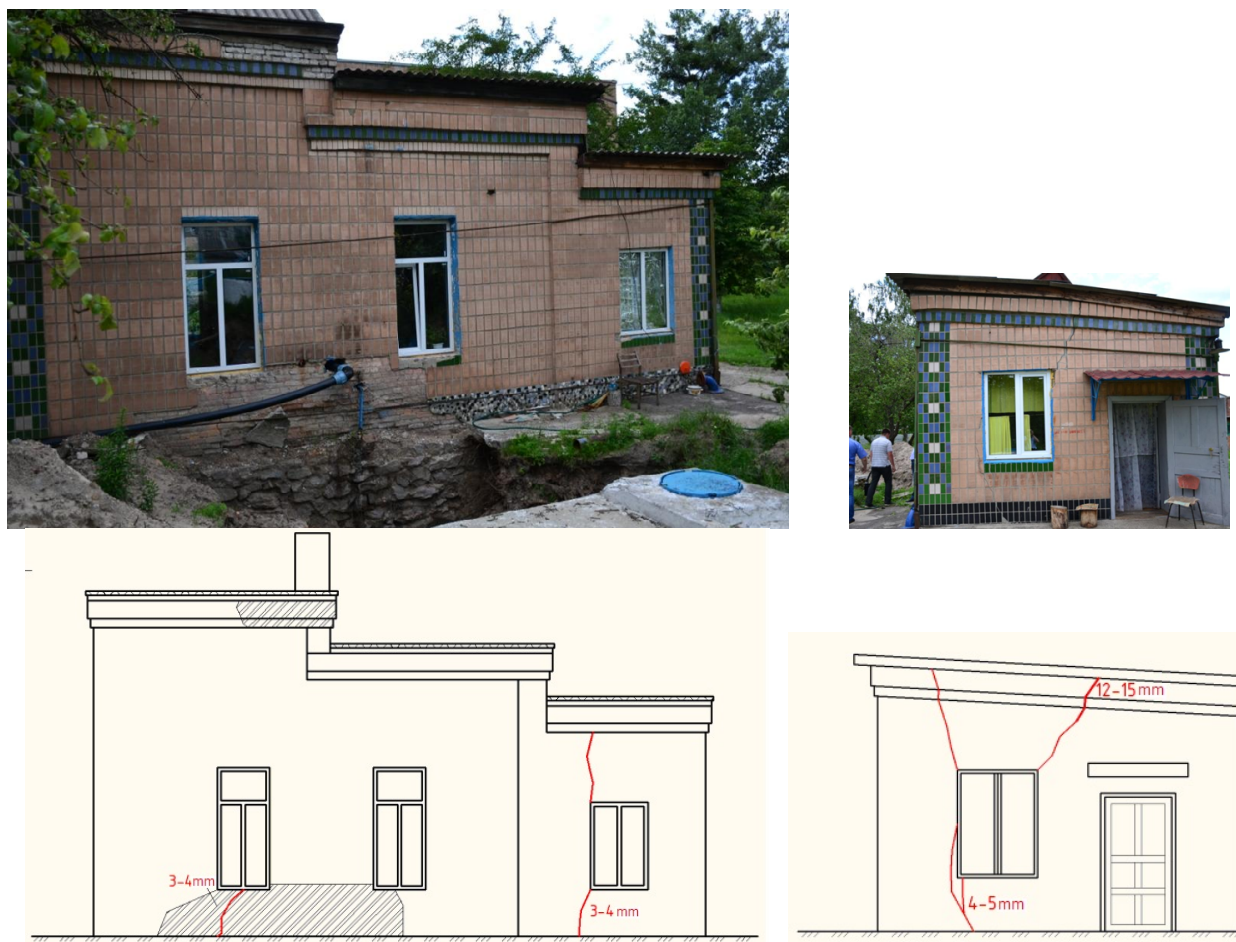

(a)

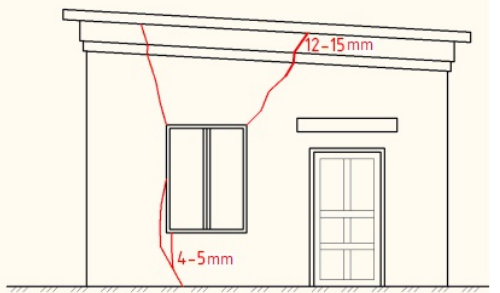

(b)

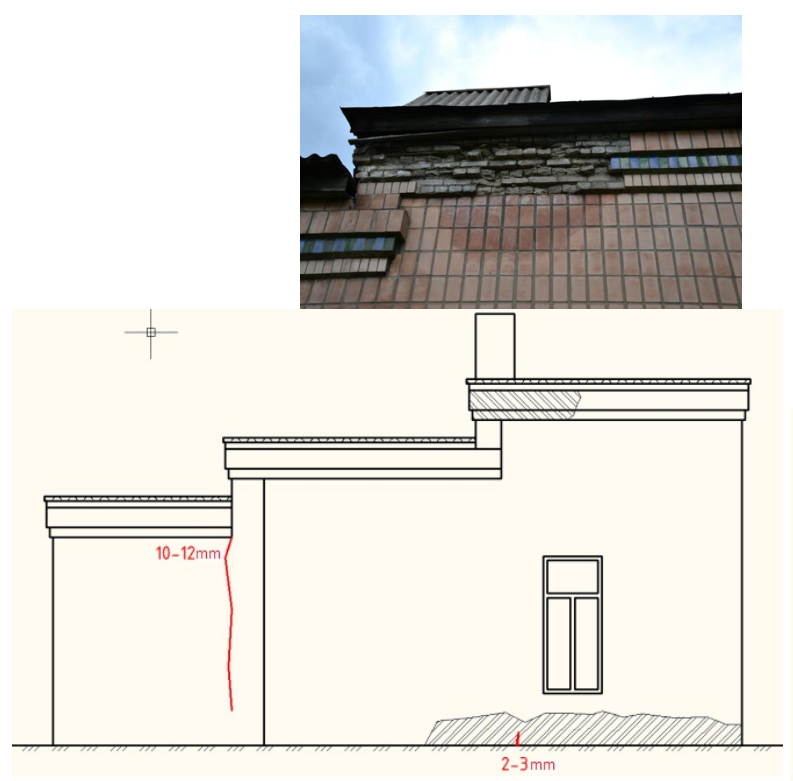

(c)

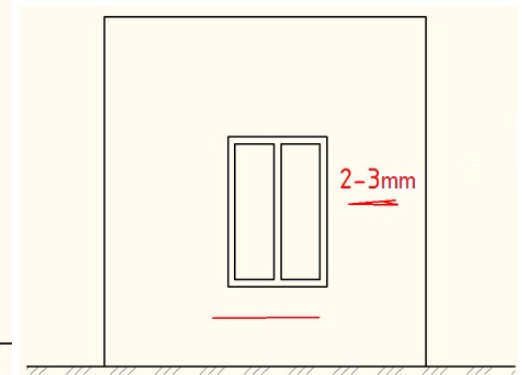

(d)

Fig.2. The pictures and maps of damages of the building facades of the water station: (a) eastern; (b) northern; (c) western and (d) southern.

In addition, when DC rail lines are located near the water well, the negative excess charge of the ground around it presupposes the intensification of the electrocorrosion of rail 
fastening, reinforced concrete ties, foundations, support butts of overhead contact systems, etc. To prevent this, we recommend using the superstructure design for the railways and tram roads with the isolated rail or on isolated blocks [19].

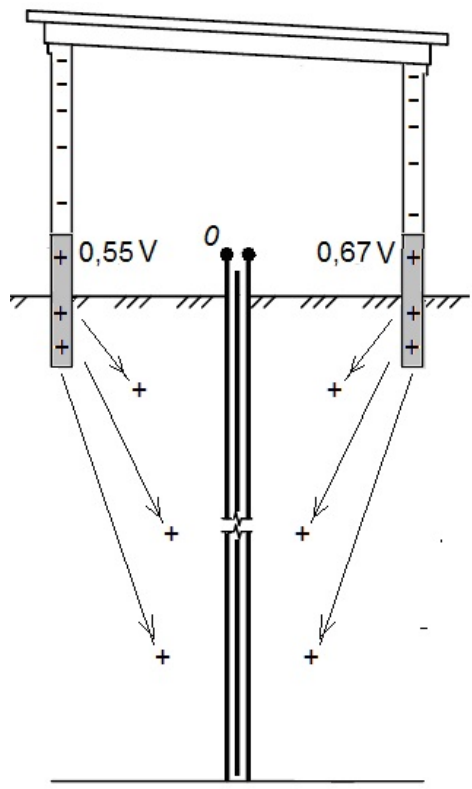

Fig. 3. The diagram of entrainment of cations $\mathrm{Ca}^{2+}$ from the foundation and walls of buildings.

\section{Conclusions and recommendations}

It has been established that exploitable water wells condition the separation of electric charges and potentials in the locality due to the origination of macroelectrokinetic potential and the entrainment of cations from the ground. The potentials around the explored well are changed from positive values of $0.55-0.67 \mathrm{~V}$ near the well to negative $0.39-0.4 \mathrm{~V}$ as the distance to the well increases. These charges and potentials can result in the nonuniform strain of bases and foundations, formation of cracks and damages to the structure of buildings situated above the wells and near them and also in intensive electrocorrosion of structures situated near DC rail lines.

To prevent such damages to buildings a qualitative horizontal waterproofing should be provided not only at a level of the base top, but also at a level of the riprap. We recommend investigating the possibility of bypassing the pipe casing and building structures.

To prevent the electrocorrosion of rail fastening, reinforced concrete ties, foundations, and support butts for overhead contact systems near the water wells, we recommend using the superstructure design for the railways and tram roads with the isolated rail.

\section{References}

1. I.A. Kornfel'd, V.A. Pritula, Zashchita zhelezobetonnykh konstruktsiy ot elektrokorrozii, vyzyvayemoy bluzhdayushchimi tokami (Stroyizdat, Moscow, 1964)

2. A.V. Kotel'nikov, Bluzhdayushchiye toki elektrifitsirovannogo transporta (Transport, Moscow, 1986)

3. A.A. Starosel'skiy, Elektrokorroziya zhelezobetona (Budivel'nik, Kyiv, 1978) 
4. O.A. Pluhin, O.S. Borzyak, V.B. Martinova, O.K. Khalyushev, Yelektrichni vplivi na beton, ed. A.A. Plugin and M.M. Zaychenko (Fort, Kharkiv, 2013)

5. A.N. Plugin, A.A. Plugin, O.A. Pluhin, O.A. Dudin, O.S. Borzyak, 17 Internationale Baustofftagung, Weimar, 2 (2009).

6. O.A. Pluhin, Zbirnik naukovih prac' Ukrainian State Academy of Railway Transport, 115 (2010)

7. A.N. Ostapenko, Transport of Ural, 4, 31 (2011)

8. A.N. Plugin, A.A. Plugin, O.A. Dudin, O.A. Pluhin, O.S. Borzyak, A.A. Konev, Visnyk Odes'koyi derzhavnoyi akademiyi budivnytstva i arkhitektury, 43 (2010)

9. O.A. Pluhin, A.A. Zabiyaka, V.V. Perestyuk, S.G. Nesterenko, A.A. Plugin, Zbirnik naukovih prac' Ukrainian State Academy of Railway Transport, 130 (2012)

10. A.N. Plugin, A.A. Plugin, O.A. Pluhin, A.A. Konev, A.A. Zabiyaka, Zbirnik naukovih prac' Ukrainian State Academy of Railway Transport, 138 (2013)

11. O.A. Pluhin, A.N. Plugin, A.A. Plugin, A.A. Konev, A.A. Zabiyaka, Zbirnik naukovih prac' Ukrainian State Academy of Railway Transport, 142 (2013)

12. A.A. Plugin, O.A. Zabiyaka, G.O. Linnik, Zbirnik naukovih prac' Ukrainian State Academy of Railway Transport, 115 (2010)

13. A.N. Plugin, L.V. Trykoz, O.S. Herasimenko, A.A. Plugin, D.A. Plugin, O.A. Pluhin, Visnyk Dnipropetrovs'koho natsional'noho universytetu zaliznychnoho transportu im. V. Lazaryana, 39 (2011)

14. A.A. Plugin, A.M. Plugin, L.V. Trykoz, O.S. Herasimenko, Railway Transport of Ukraine, 5 (2010).

15. L.V. Trykoz, O.S. Herasimenko, Eastern European Journal of Enterprise Technology, 4/5, 70 (2014)

16. A.N. Plugin, L.V. Trykoz, A.A. Plugin, D.A. Plugin, A.A. Konev, O.S. Borzyak, Zbirnik naukovih prac' Ukrainian State Academy of Railway Transport, 148, 2 (2014)

17. A.N. Plugin, A.A. Plugin, L.V. Trykoz, D.A. Plugin, O.A. Pluhin, Railway Transport of Ukraine, 2 (2014)

18. Ye.D. Shchukin, F.V. Pertsov, Ye.A. Amelina, Kolloidnaya khimiya, ed. 4 (Vysshaya shkola, Moscow, 2006)

19. T. Shuba, V. Chystyak, V. Perestyuk, O. Yelyakina (Palant), O.A. Zabiyaka, A.A. Plugin, Zbirnik naukovih prac' Ukrainian State Academy of Railway Transport, 122 (2011) 